\title{
Dust exposure and mortality in chrysotile mining, 1910-75
}

\author{
J C MCDONALD, 1 F D K LIDDELL, 2 G W GIBBS, ${ }^{2}$ G E EYSSEN, 2 AND \\ A D MCDONALD ${ }^{3}$
}

\begin{abstract}
From the TUC Centenary Institute of Occupational Health, London School of Hygiene and Tropical Medicine, London, UK, ${ }^{1}$ the Department of Epidemiology and Health, McGill University, Montreal, Canada, ${ }^{2}$ and the Department of Epidemiology, St Mary's Hospital Medical School, London, UK ${ }^{3}$
\end{abstract}

ABSTRACT We report a further follow-up of a birth cohort of 11379 workers exposed to chrysotile. The cohort consisted of all 10939 men and 440 women, born 1891-1920, who had worked for at least a month in the mines and mills of Asbestos and Thetford Mines in Quebec. For all subjects, length of service and estimates of accumulated dust exposure were obtained, with a smoking history for the vast majority. Three methods of analysis, two based on the "man-years" method, the other a "case-and-multiple-controls" approach, gave results consistent with one another and with previous analyses.

By the end of 1975, 4463 men and 84 women had died. Among men, the overall excess mortality, 1926-75, was $2 \%$ at Asbestos and $10 \%$ at Thetford Mines, much the dustier region. The women, mostly employed at Asbestos, had a standardised mortaiity ratio (SMR) (all causes, 1936-75) of 0.90. Analysis of deaths 20 years or more after first employment showed that in men with short service (less than five years) there was no discernible correlation with dust exposure. Among men employed at least 20 years, there were clear excesses in those exposed to the heaviest dust concentrations. Reanalysis in terms of exposure to age 45 showed definite and consistent trends for SMRs for total mortality, for lung cancer, and for pneumoconiosis to be higher the heavier the exposure. The response to increasing dose was effectively linear for lung cancer and for pneumoconiosis. Lung cancer deaths occurred in non-smokers, and showed a greater increase of incidence with increasing exposure than did lung cancer in smokers, but there was insufficient evidence to distinguish between multiplicative and additive risk models. There were no excess deaths from laryngeal cancer, but a clear association with smoking. Ten men and one woman died from pleural mesothelioma.

If the only subjects studied had been the 1904 men with at least 20 years' employment in the lower dust concentrations, averaging 6.6 million particles per cubic foot (or about 20 fibres/cc), excess mortality would not have been considered statistically significant, except for pneumoconiosis. The inability of such a large epidemiological survey to detect increased risk at what, today, are considered unacceptable dust concentrations, and the consequent importance of exposure-response models are therefore emphasised.

Mining, milling, and processing of the asbestos group of fibrous minerals, long known for their remarkable strength and fire resistance, began on a commercial scale at the end of the nineteenth century. In the Eastern Townships region of Quebec deposits of chrysotile were noted in the 1847 Canadian Geological Survey. Exploitation began at

Received 12 January 1979

Accepted 11 April 1979
Thetford in 1878 and four years later some 60 miles away near Danville. Within 30 years the region was producing most of the world's asbestos. The proportion fell as Russian, South African, and Italian mines came into operation, but Quebec still produces about $25 \%$ of the world's supply, now estimated at about six million tons a year; indeed, production in Quebec and elsewhere has continued to expand.

In and around Thetford many companies started mining, and the town was renamed Thetford Mines. 
Amalgamations and closures over the years reduced the number of companies to six. One large company has operated near Danville, and the new town of Asbestos was built; this company has also manufactured asbestos products in a small local factory. There was formerly a small mine a few miles away, owned by another company, which is included with the companies of the Thetford area for the purposes of this paper.

Attention drawn at the New York Academy of Sciences in 1964 to the serious threats to health posed by airborne asbestos dust led immediately to recommendations ${ }^{1}$ that epidemiological inquiries were urgently needed in populations exposed to single types of fibres. At the invitation of the Canadian Government, and with encouragement from the Government of Quebec, a research programme was established in 1966 at McGill University to study the health effects of work in the Quebec chrysotile-producing industry. Results of the first three years' work, which included the reading of 16000 chest radiographs, comprehensive tests on a sample of current workers, and studies of mortality to the end of 1966 were summarised by McDonald et al in $1974 .^{2}$

Our knowledge of the mortality experienced by chrysotile workers is derived from observations on a birth cohort (1891-1920) of 10939 men and 440 women, followed from first employment (the earliest in 1904) to the end of 1975 , by which time 4463 men and 84 women were known to have died. The first death was due to an accident in 1910, and another 112 men died before the end of 1925 , mainly through accidents or respiratory tuberculosis. During the five decades, 1926-75, 4350 men died compared with 4107 expected on the basis of Quebec age- and year-specific death rates, a standardised mortality ratio (SMR) of 1.06 , but the evolution of mortality in the cohort differed substantially in the two mining areas. ${ }^{3}$ Table 1 shows that there were almost equal numbers of employees in the two mining areas, Asbestos and Thetford Mines. The numbers in each of the six quinquennia of birth were similar, varying only between 1509 and 1969 . The first excesses, which were during the war years, were about equal in the two areas, and may have been attributable, at least in part, to the exclusion, until 1944, from the Quebec vital statistics of deaths in military personnel outside Canada. In the decade 1946-55 there were 42 fewer deaths than expected at Asbestos but 16 more than expected at Thetford Mines. From 1956 to 1970 there were excesses in both areas, but considerably less at Asbestos (78) than at Thetford Mines (173). In the final period, 1971-5, there were 18 fewer deaths than expected at Asbestos, but still an excess of 12 at Thetford Mines. During the five decades, 1926-75, there had been a net excess of 33.9 deaths at Asbestos (1.6\% of the 2074.1 expected) and of 208.8 at Thetford Mines $(10.3 \%$ of 2033.2) -that is, SMRs of 1.02 and 1.10 respectively.

The primary aim of the mortality survey was "to define as accurately as possible the quantitative relationship between exposure to chrysotile asbestos and the incidence of lung cancer." 4 The present paper reports the results of the follow-up until the end of 1975. Mortality from lung cancer is associated with smoking, and the concern must be to attempt to separate the hazards. It is also important to consider total mortality, if only to confirm that an excess of deaths from lung cancer does not blind us to a shortfall of greater magnitude from other causes, as has sometimes occurred in other surveys. Additional aims were to measure exposure-response relations for other malignant diseases, particularly cancers of the gastrointestinal tract and larynx, and for pneumoconiosis and other respiratory diseases.

\section{Material and methods}

In November 1966 a register was compiled of everyone, nearly 30000 , ever employed in the Quebec chrysotile production industry. A small proportion, who worked at the factory in Asbestos, were also included because of the movement of employees between it and the mine or mills. Everyone born between 1891 and 1920 inclusive and employed for one month or more was identified from the register. These criteria for admission to the cohort were chosen to ensure a wide range in levels of exposure and durations of employment, while those born before 1891 would have been particularly difficult to trace and those born after 1920 have yet to reach the age of high mortality. All available means were adopted in attempts to trace every person in the cohort $^{4}$; there was no appropriate social security system to facilitate this. For all deaths, exact dates and places were sought so that copies of death certificates could be obtained. The cause of death was coded according to the International Classification of Diseases ( 7 th revision) by a person who regularly performed this task for the Quebec Department of Vital Statistics.

Tracing has been carried out to four points in time: 31 October $1966,{ }^{4}$ to the end of $1969,{ }^{2} 5$ to the end of 1973,6 and now to the end of 1975 . The proportion traced has slightly improved over the years: most of the $9.9 \%$ still lost to view were men with short service many years ago; less than $2 \%$ were untraced after 1935. The total cohort now numbers 11379 (10939 men and 440 women) whereas it was originally estimated ${ }^{4}$ as 11788 . The reduction has been due to improving information 
which permitted (a) more stringent application of admission criteria and (b) better recognition of cases in which the same employee had been separately registered with different companies or under different names. In the nine years since our first report the number of deaths has increased from 2457 to 4547 , now comprising $44.3 \%$ of those traced. By the end of 1975 the youngest people alive in the cohort were 55 years old, the oldest 84 .

Much work was put into determining the dust exposure for each subject, as described by Gibbs and Lachance. ${ }^{7}$ In essence, some 5783 jobs were identified from detailed work histories, and for each one, for each applicable year, an average dust concentration was estimated in millions of particles per cubic foot (mpcf) from available dust measurements and approximations. Estimates were based on well over 4000 midget impinger dust counts measured, between 1949 and 1966, by Maurice Lachance, ingénieur, in annual surveys in all companies. Before 1949 there had been few measurements, so estimates were made by Gibbs and Lachance after interviews with long-service employees and comparisons with more recent conditions. her

For each person in the cohort, we defined his or

Gross service-The period from start of first job to termination of last job (or to November 1966, if earlier).

Net service-The total of periods of actual employment.

Service gap-(Gross service less net service)/ (gross service), as per cent.

Accumulated dust exposure-The total of annual dust exposures, summed over defined periods; the units are mpcf multiplied by years (mpcf $y$ ).

Smoking habit was assessed by a questionnaire, answered by $99.6 \%$ of those alive in 1970 and by the relatives or friends of $93 \%$ of those who died after 1950; for earlier deaths, numbering 816 , it was thought that smoking histories would often not be obtainable or sufficiently reliable. Each man has been classified according to his reported smoking habit at the time of report as: non-smoker, moderate smoker, or heavy smoker-that is; one who smoked 26-50 cigarettes a day.

The data to 1966 and those to 1969 were analysed primarily by a method which was recognised ${ }^{2}$ as having two weaknesses: (1) that deaths accumulated over many years were used without regard for age at death; and (2) that length of exposure was related to length of survival. These problems were covered in part by subsidiary analyses included in our first two reports 45 and in a more satisfactory but preliminary way in a third more comprehensive paper. ${ }^{2}$ Although it was appreciated that an analysis based on man- years of exposure with comparison against an external reference population ${ }^{8}$ was the orthodox approach to the problem, this too had its weaknesses. After a period of exploration and consultation, ${ }^{9}$ the 1973 mortality data were used for an appraisal of methods of cohort analysis and presented for discussion at a general meeting of the Royal Statistical Society. ${ }^{6}$ The merits and practical usefulness of the man-years method (which reasons a priori - that is, from cause to effect) were confirmed, but, clearly, an approach using a small fixed number of controls for each death, ${ }^{10}$ and arguing a posteriori (from effect to cause), had other advantages. In particular it is efficient for examining interaction between several stimulus variables-for example, smoking, dust concentration, and duration of employment-and it does not depend on the availability of death rates for a reference population. Although rates for Quebec have been available since 1926, the appropriateness of this or any other reference population has always to be questioned. In this latest report we have used both methods; in addition we have made use of certain findings from the detailed analyses of deaths to the end of 1973 by Liddell et al. ${ }^{6}$

\section{A PRIORI ANALYSES}

For the man-years method, and to avoid possibly misleading non-standard terminology, we have continued to use the following definitions.

Subcohort-A division of the cohort, according to some factor(s) such as years of exposure or smoking habit.

Study interval-The interval over which each subject is studied in a particular facet of the studywhich is not necessarily the same as the period over which the subject has been in view.

There are several aims, mainly conflicting, in the definition of subcohorts: they should be mutually exclusive and comprehensive, fairly equal in size, and large enough to provide reliable measures of mortality yet small enough to be homogeneous, preferably with at last three classes of each factor of interest in the relations of dose to response. There are usually several such factors, however, and their interactions may be important, so that many subcohorts are necessary. The compromises adopted are described below.

For a first series of analyses, the male cohort was subdivided initially by length of gross service, the boundaries being taken at one year, five years, and 20 years; thereafter, each gross service group was divided into four more-or-less equal classes according to accumulated dust exposure. For those with very short service (less than one year), the three margins between the dust groups were drawn at 1,3 , and 10 mpcf.y; for those with short service (one to five 
years), the margins were at 6,30 , and 100 mpcf $\cdot y$; and for medium service (five to 20 years), at 30, 100, and $\mathbf{3 0 0} \mathrm{mpcf} \cdot \mathrm{y}$. For the long-service group (at least 20 years), the classification, with boundaries at 100 , 300 , and 600 mpcf.y, was made in terms of dust exposure accumulated in the first 20 years from start of service. The study interval for this first series of analyses started, in all four service groups, at 20 years after first employment in the industry, thus excluding only 21 deaths due to asbestos-related disease that had occurred within the first 20 years.

Relative risks of lung cancer were considered in detail by Liddell $e t$ al, ${ }^{6}$ and it appeared that there was little to suggest that the way in which dust exposure had been accumulated played any part in determining the risk. It therefore seemed appropriate to base a second series of analyses on dust exposure accumulated to a certain age, arbitrarily taken as $\mathbf{4 5}$ years, at which age most men had completed their service. After the cohort had been divided by exposure to age 45 , two further, but separate, subdivisions were made by mining area (Asbestos and Thetford Mines) and by smoking habit; those whose smoking habit was unknown being added to the largest group - that is, moderate smokers. The study interval started at age 45 .

From data for Quebec, obtained from Statistics Canada, we assembled mid-year populations and deaths from all causes in five-year age-groups (15-84) for men for the years 1926 through 1974, and for women for the years from 1936, the earliest practicable year, to 1974 ; the material for the last year was duplicated to provide estimates for 1975 . Statistics Canada also provided magnetic tapes containing age, sex, and cause of all Quebec deaths, 1951-73, coded to the International Classification of Diseases for the 12 specific groups of causes defined in table 2. The numbers of deaths for "other known causes" were obtained by subtraction. Annual death rates for the reference population were calculated for five-year age-groups, 15-84, from the mid-year populations, 1951-75; those for 1973 were replicated twice to give estimates for 1974 and 1975.

\section{A POSTERIORI ANALYSIS}

The Miettinen method ${ }^{10}$ uses a fixed number of controls for each case of interest. Our selection of internal controls was strictly at random from among those miners known to have survived to a greater age than that at which the case died and to have been born in (or as close as possible to) the same year as the case. Each control came from the same mining area as the case; for some purposes, one control was matched for smoking habit with the case. Those of unknown or doubtful habit were classified as "undifferentiated" and three groups of definite smokers were considered in the matching-that is, those smoking 15-25, 26-35, and 36-50 cigarettes a day. An attempt was made to match precisely into the subgroups, but for definite smokers relaxation was not infrequently necessary, and indeed in a few cases the control had to be found from the "undifferentiated" class.

The causes of death studied in this way, with the numbers of controls selected with and without regard for smoking were as follows: pneumoconiosis $(1,3)$; lung cancer $(1,3)$; abdominal cancers $(0,2)$; laryngeal cancers $(1,3)$; and mesothelioma $(1,4)$. For these analyses, the dust exposure was calculated up to nine years before the death of each case and to the same age for his controls.

\section{Results}

\section{MEN}

Just under half the men from each area were known to be alive in 1976, but one-tenth had been lost to view (table 1). Most of these losses were before 1936; in a review of the situation when tracing had been completed to the end of 1973 it was found that of 9723 men known to have been alive in 1936, 5797 had been traced alive, 3750 were known to have died, and only 176 were untraced $(59.6 \%, 38.6 \%$, and $1.8 \%$, respectively).

Table 1 Constitution of male cohort at end of 1975. (Percentages in parentheses)

\begin{tabular}{lccc}
\hline & Asbestos & $\begin{array}{l}\text { Thetford } \\
\text { Mines }\end{array}$ & $\begin{array}{l}\text { Complete } \\
\text { cohort }\end{array}$ \\
\hline Alive & $2608(49 \cdot 2)$ & $2779(49 \cdot 3)$ & $5387(49 \cdot 2)$ \\
Dead & $2179(41 \cdot 1)$ & $2284(40 \cdot 5)$ & $4463(40 \cdot 8)$ \\
Lost to view & $515(9 \cdot 7)$ & $574(10 \cdot 2)$ & $1089(10 \cdot 0)$ \\
Total & $5302(100)$ & $5637(100)$ & $10939(100)$ \\
\hline
\end{tabular}

The 4463 male deaths are shown in table 2 by year, age, and certified cause, Deaths from pneumoconiosis and lung cancer were generally at ages over 45 and from 1956 onwards. Respiratory tuberculosis was a major cause of death until the early 1950s, while accidents (including, but not dominated by, accidents at work) have been a common cause of death throughout, particularly in those under 45 . In a total of 125 deaths $(2.8 \%$ of all deaths), cause could not be ascertained, partly because death registration was not universal in Quebec until 1926, and partly because some death certificates were not found.

The number of death certificates on which it was stated that a necropsy had been carried out was 789 
Dust exposure and mortality in chrysotile mining, 1910-75

Table 2 Deaths of men, by year, age, and certified cause of death

\begin{tabular}{|c|c|c|c|c|c|c|c|}
\hline \multirow[t]{2}{*}{ Cause of death (ICD code*) } & \multirow[t]{2}{*}{ Age at death } & \multicolumn{6}{|l|}{ Year of death } \\
\hline & & Before 1946 & $1946-55$ & $1956-65$ & $1966-75$ & Total & \\
\hline All causes & $\begin{array}{c}<45 \\
45-64 \\
\geqslant 65\end{array}$ & $\begin{array}{l}564 \\
111 \\
-\end{array}$ & $\begin{array}{l}136 \\
438 \\
-\end{array}$ & $\begin{array}{r}54 \\
842 \\
389\end{array}$ & $\begin{array}{r}\overline{702} \\
1227\end{array}$ & $\left.\begin{array}{r}754 \\
2093 \\
1616\end{array}\right\}$ & 4463 \\
\hline $\begin{array}{l}\text { Pneumoconiosis } \\
\quad(523-524)\end{array}$ & $\begin{array}{l}<45 \\
45.64 \\
\geqslant 65\end{array}$ & $\begin{array}{r}0 \\
1 \\
-\end{array}$ & $\begin{array}{r}\mathbf{0} \\
\mathbf{6} \\
-\end{array}$ & $\begin{array}{r}1 \\
10 \\
7\end{array}$ & $\begin{array}{r}- \\
13 \\
8\end{array}$ & $\left.\begin{array}{c}1 \\
30 \\
15\end{array}\right\}$ & 46 \\
\hline $\begin{array}{l}\text { Malignant neoplasms: } \\
\text { Lung }(162-164)\end{array}$ & $\begin{array}{c}<45 \\
45-64 \\
\geqslant 65\end{array}$ & $\begin{array}{r}2 \\
0 \\
-\end{array}$ & $\begin{array}{r}2 \\
12 \\
-\end{array}$ & $\begin{array}{r}2 \\
51 \\
20\end{array}$ & $\begin{array}{l}\overline{72} \\
89\end{array}$ & $\left.\begin{array}{r}6 \\
135 \\
109\end{array}\right\}$ & 250 \\
\hline $\begin{array}{l}\text { Oesophagus and stomach } \\
(150-151)\end{array}$ & $\begin{array}{c}<45 \\
45-64 \\
\geqslant 65\end{array}$ & $\begin{array}{r}5 \\
-4 \\
-\end{array}$ & $\begin{array}{r}22 \\
22 \\
-\end{array}$ & $\begin{array}{r}1 \\
34 \\
12\end{array}$ & $\begin{array}{l}-17 \\
57\end{array}$ & $\left.\begin{array}{r}8 \\
77 \\
69\end{array}\right\}$ & 154 \\
\hline $\begin{array}{l}\text { Colon and rectum } \\
(152-154)\end{array}$ & $\begin{array}{c}<45 \\
45-64 \\
\geqslant 65\end{array}$ & $\begin{array}{r}4 \\
-1 \\
-\end{array}$ & $\begin{array}{r}1 \\
-8\end{array}$ & $\begin{array}{r}0 \\
20 \\
6\end{array}$ & $\begin{array}{l}\overline{18} \\
30\end{array}$ & $\left.\begin{array}{r}5 \\
47 \\
36\end{array}\right\}$ & 88 \\
\hline $\begin{array}{l}\text { Other abdominal } \\
\text { (155-159) }\end{array}$ & $\begin{array}{c}<45 \\
45-64 \\
\geqslant 65\end{array}$ & $\begin{array}{r}5 \\
1 \\
-\end{array}$ & $\begin{array}{r}2 \\
6 \\
-\end{array}$ & $\begin{array}{r}1 \\
15 \\
6\end{array}$ & $\begin{array}{l}\overline{14} \\
30\end{array}$ & $\left.\begin{array}{r}8 \\
36 \\
36\end{array}\right\}$ & 80 \\
\hline $\begin{array}{l}\text { Larynx } \\
\text { (161) }\end{array}$ & $\begin{array}{l}<45 \\
45-64 \\
\geqslant 65\end{array}$ & $\begin{array}{r}\mathbf{0} \\
\mathbf{2}^{2}\end{array}$ & $\begin{array}{r}0 \\
-5 \\
-\end{array}$ & $\begin{array}{l}0 \\
6 \\
1\end{array}$ & $\begin{array}{r}- \\
5 \\
2\end{array}$ & $\left.\begin{array}{r}0 \\
18 \\
3\end{array}\right\}$ & 21 \\
\hline $\begin{array}{l}\text { Other } \\
(140-148 ; 160 ; 165-205)\end{array}$ & $\begin{array}{c}<45 \\
45-64 \\
\geqslant 65\end{array}$ & $\begin{array}{r}12 \\
2 \\
-\end{array}$ & $\begin{array}{r}4 \\
28 \\
-\end{array}$ & $\begin{array}{r}1 \\
52 \\
28\end{array}$ & $\begin{array}{r}- \\
48 \\
101\end{array}$ & $\left.\begin{array}{r}17 \\
130 \\
129\end{array}\right\}$ & 276 \\
\hline $\begin{array}{l}\text { Heart disease } \\
(400-443)\end{array}$ & $\begin{array}{l}<45 \\
45-64 \\
\geqslant 65\end{array}$ & $\begin{array}{r}28 \\
25 \\
-\end{array}$ & $\begin{array}{r}25 \\
154 \\
-\end{array}$ & $\begin{array}{r}18 \\
355 \\
166\end{array}$ & $\begin{array}{l}\overline{285} \\
487\end{array}$ & $\left.\begin{array}{r}71 \\
819 \\
653\end{array}\right\}$ & 1543 \\
\hline $\begin{array}{l}\text { Respiratory tuberculosis } \\
(001-008)\end{array}$ & $\begin{array}{l}<45 \\
45.64 \\
\geqslant 65\end{array}$ & $\begin{array}{r}118 \\
20 \\
-\end{array}$ & $\begin{array}{r}30 \\
31 \\
-\end{array}$ & $\begin{array}{r}1 \\
27 \\
5\end{array}$ & $\begin{array}{r}- \\
9\end{array}$ & $\left.\begin{array}{r}149 \\
85 \\
14\end{array}\right\}$ & 248 \\
\hline $\begin{array}{l}\text { Other respiratory } \\
(470-522 ; 525-527)\end{array}$ & $\begin{array}{c}<45 \\
45-64 \\
\geqslant 65\end{array}$ & $\begin{array}{r}60 \\
5 \\
-\end{array}$ & $\begin{array}{r}3 \\
12 \\
-\end{array}$ & $\begin{array}{r}0 \\
28 \\
17\end{array}$ & $\begin{array}{l}-37 \\
72\end{array}$ & $\left.\begin{array}{l}63 \\
82 \\
89\end{array}\right\}$ & 234 \\
\hline $\begin{array}{l}\text { Cerebrovascular } \\
(330-334)\end{array}$ & $\begin{array}{c}<45 \\
45-64 \\
\geqslant 65\end{array}$ & $\begin{array}{r}6 \\
-4\end{array}$ & $\begin{array}{r}2 \\
12 \\
-\end{array}$ & $\begin{array}{c}3 \\
42 \\
39\end{array}$ & $\begin{array}{c}-38 \\
122\end{array}$ & $\left.\begin{array}{c}11 \\
96 \\
161\end{array}\right\}$ & 268 \\
\hline $\begin{array}{l}\text { Accidents } \\
\text { (800-999) }\end{array}$ & $\begin{array}{l}<45 \\
45-64 \\
\geqslant 65\end{array}$ & $\begin{array}{r}170 \\
18 \\
-\end{array}$ & $\begin{array}{r}41 \\
44 \\
-\end{array}$ & $\begin{array}{r}17 \\
71 \\
9\end{array}$ & $\begin{array}{l}\overline{51} \\
40\end{array}$ & $\left.\begin{array}{r}228 \\
184 \\
49\end{array}\right\}$ & 461 \\
\hline All other known causes & $\begin{array}{l}<45 \\
45-64 \\
\geqslant 65\end{array}$ & $\begin{array}{r}114 \\
25 \\
-\end{array}$ & $\begin{array}{l}23 \\
82 \\
-\end{array}$ & $\begin{array}{r}9 \\
112 \\
67\end{array}$ & $\begin{array}{r}-82 \\
155\end{array}$ & $\left.\begin{array}{l}146 \\
301 \\
222\end{array}\right\}$ & 669 \\
\hline Cause not known & $\begin{array}{l}<45 \\
45-64 \\
\geqslant 65\end{array}$ & $\begin{array}{r}40 \\
-3 \\
-\end{array}$ & $\begin{array}{r}1 \\
16 \\
-\end{array}$ & $\begin{array}{r}0 \\
19 \\
6\end{array}$ & $\begin{array}{r}- \\
15 \\
25\end{array}$ & $\left.\begin{array}{l}41 \\
53 \\
31\end{array}\right\}$ & 125 \\
\hline
\end{tabular}

* Code in the 7th revision of the International Classification of Diseases.

$(17.7 \%$ of all deaths), and necropsy reports were obtained for the majority. These showed nine extra cases of lung cancer, but to maintain comparability with the general population only the coded causes of death were used throughout. Ten male deaths due to pleural mesothelioma were identified, nine from death certificates and one at necropsy. Six of these had been coded to lung cancer (ICD 162 or 163).

Table 3 describes the cohort by duration of employment; generally shorter at Asbestos than at Thetford Mines. In table 4 the four service groups have been further subdivided, as described in the 
Table 3 Gross service of men, by mining area. (Percentages in parentheses)

\begin{tabular}{lllr}
\hline $\begin{array}{l}\text { Length of gross } \\
\text { service }(y r)\end{array}$ & Asbestos & $\begin{array}{l}\text { Thetford } \\
\text { Mines }\end{array}$ & $\begin{array}{l}\text { Complete } \\
\text { cohort }\end{array}$ \\
\hline Very short $(<1)$ & $1783(33 \cdot 6)$ & $1224(21 \cdot 7)$ & $3007(27 \cdot 5)$ \\
Short $(1-<5)$ & $1215(22 \cdot 9)$ & $1109(19 \cdot 7)$ & $2324(21 \cdot 2)$ \\
Medium $(5-<20)$ & $1147(21 \cdot 6)$ & $1356(24 \cdot 1)$ & $2503(22 \cdot 9)$ \\
Long $(\geqslant 20)$ & $1157(21 \cdot 8)$ & $1948(34 \cdot 6)$ & $3105(28 \cdot 4)$ \\
Total & $5302(100)$ & $5637(100)$ & $10939(100)$ \\
\hline
\end{tabular}

Table 4 Age at start and duration of employment, with dust exposure. (Numbers of men, with average age at start of employment, average gross and net service, in years, and average dust "concentration")

\begin{tabular}{|c|c|c|c|c|c|}
\hline \multirow[t]{2}{*}{$\begin{array}{l}\text { Length of gross } \\
\text { service }(y, r)\end{array}$} & & \multicolumn{4}{|c|}{$\begin{array}{l}\text { Accumulated dust exposure } \\
\text { (see text) }\end{array}$} \\
\hline & & Low & Medium & High & $\begin{array}{l}\text { Very } \\
\text { high }\end{array}$ \\
\hline $\begin{array}{l}\text { Very short } \\
(<1)\end{array}$ & $\begin{array}{l}\text { No } \\
\text { Age at start } \\
\text { Gross service } \\
\text { Net service } \\
\text { Concentration* }\end{array}$ & $\begin{array}{c}1022 \\
26 \cdot 3 \\
0 \cdot 2 \\
0 \cdot 2 \\
2 \cdot 6\end{array}$ & $\begin{array}{l}838 \\
26 \cdot 1 \\
0 \cdot 4 \\
0 \cdot 4 \\
4 \cdot 3\end{array}$ & $\begin{array}{r}571 \\
24.9 \\
0.4 \\
0.4 \\
14.4\end{array}$ & $\begin{array}{r}576 \\
22 \cdot 9 \\
0 \cdot 5 \\
0 \cdot 5 \\
78 \cdot 0\end{array}$ \\
\hline $\begin{array}{l}\text { Short } \\
(1-<5)\end{array}$ & $\begin{array}{l}\text { No } \\
\text { Age at start } \\
\text { Gross service } \\
\text { Net service } \\
\text { Concentration* }\end{array}$ & $\begin{array}{c}593 \\
28 \cdot 6 \\
1 \cdot 7 \\
1 \cdot 3 \\
2 \cdot 5\end{array}$ & $\begin{array}{r}367 \\
26 \cdot 1 \\
2 \cdot 5 \\
2 \cdot 2 \\
6 \cdot 2\end{array}$ & $\begin{array}{r}484 \\
23 \cdot 5 \\
2 \cdot 6 \\
2 \cdot 5 \\
23 \cdot 6\end{array}$ & $\begin{array}{r}380 \\
20 \cdot 8 \\
3 \cdot 0 \\
2 \cdot 8 \\
82 \cdot 6\end{array}$ \\
\hline $\begin{array}{l}\text { Medium } \\
(5-<20)\end{array}$ & $\begin{array}{l}\text { No } \\
\text { Age at start } \\
\text { Gross service } \\
\text { Net service } \\
\text { Concentration* }\end{array}$ & $\begin{array}{r}714 \\
28 \cdot 6 \\
9 \cdot 5 \\
6 \cdot 4 \\
2 \cdot 5\end{array}$ & $\begin{array}{l}758 \\
27 \cdot 7 \\
12 \cdot 4 \\
10 \cdot 4 \\
5 \cdot 6\end{array}$ & $\begin{array}{l}544 \\
24 \cdot 5 \\
12 \cdot 2 \\
10 \cdot 5 \\
17 \cdot 0\end{array}$ & $\begin{array}{l}487 \\
22 \cdot 3 \\
12 \cdot 4 \\
11 \cdot 3 \\
62 \cdot 3\end{array}$ \\
\hline $\begin{array}{l}\text { Long } \\
(\geqslant 20)\end{array}$ & $\begin{array}{l}\text { No } \\
\text { Age at start } \\
\text { Gross service } \\
\text { Net service } \\
\text { Concentration }\end{array}$ & $\begin{array}{r}1037 \\
24 \cdot 1 \\
31 \cdot 3 \\
24 \cdot 9 \\
4 \cdot 2\end{array}$ & $\begin{array}{l}867 \\
23 \cdot 0 \\
31 \cdot 6 \\
27 \cdot 8 \\
9 \cdot 4\end{array}$ & $\begin{array}{l}565 \\
22 \cdot 3 \\
31 \cdot 6 \\
28 \cdot 6 \\
19 \cdot 2\end{array}$ & $\begin{array}{l}636 \\
21 \cdot 6 \\
33 \cdot 4 \\
30 \cdot 8 \\
46 \cdot 8\end{array}$ \\
\hline
\end{tabular}

* Found as average of dust exposure accumulated over gross service divided by average net service and expressed as million particles per cubic foot (mpcf).

previous section. In making these subdivisions priority was given to keeping subcohorts of adequate size for analysis, rather than to maintaining the same boundaries between dust concentration categories. Table 4 shows, nevertheless, that the mean concentrations (mpcf) in each set of four did not range very widely: low: $2 \cdot 5$ to $4 \cdot 2$; medium: $4 \cdot 3$ to $9 \cdot 4$; high: $14 \cdot 4$ to $23 \cdot 6$; very high: $46 \cdot 8$ to $82 \cdot 6$.

Dust concentrations have always been lower at Asbestos than at Thetford Mines. Thus to qualify for high dust exposure men at Asbestos had to have started work earlier or to have had longer service, particularly net service; gaps (as recorded) also were shorter, proportionately, at Asbestos. For the second form of a priori analysis, the men were classified by their dust exposure accumulated to age 45 (table 5). There is recent evidence that a very few employment gaps, some due to war service, did not appear in the work histories at Asbestos, and so exposures may be slightly overstated there. Nevertheless, table 5 shows a substantially lower proportion of men at Asbestos with exposures.greater than $300 \mathrm{mpcf} \cdot \mathrm{y}$.

Table 5 Dust exposure accumulated to age 45. (Percentages in parentheses)

\begin{tabular}{lrll}
\hline $\begin{array}{l}\text { Dust exposure }(m p c f \cdot y) \\
\text { accumulated to } \\
\text { age } 45 \text { years }\end{array}$ & Asbestos & $\begin{array}{l}\text { Thetford } \\
\text { Mines }\end{array}$ & $\begin{array}{l}\text { Complete } \\
\text { cohort }\end{array}$ \\
\hline$<30$ & $2954(55 \cdot 7)$ & $2532(44 \cdot 9)$ & $5486(50 \cdot 2)$ \\
$30-<300$ & $1686(31 \cdot 8)$ & $2027(36 \cdot 0)$ & $3713(33 \cdot 9)$ \\
$\geqslant 300$ & $662(12 \cdot 5)$ & $1078(19 \cdot 1)$ & $1740(15 \cdot 9)$ \\
Total & $5302(100)$ & $5637(100)$ & $10939(100)$ \\
\hline
\end{tabular}

Despite some difficulties in the classification of smoking histories (mainly because these had not been obtained for most of those lost to view nor for about 800 men who had died before 1950) but also because of certain coding errors ${ }^{6}$ (which we did not consider important enough to correct) there appear to have been only small differences between the two mining areas, and no major association between smoking habit and dust exposure to age 45 . There were, however, clear differences in the reported smoking habits of the men born in the six quinquennia: the proportion of non-smokers was $24.9 \%$ among those born 1891-5 and lower in each succeeding quinquennium, being only $9.3 \%$ among those born 1916-20; correspondingly, the proportions of heavy smokers rose in each quinquennium, from $2.9 \%$ to $12.3 \%$.

Tables 6 and 7 analyse the 3291 deaths, 20 or more years after first employment, occurring from 1951 to 75 . Comparison with table 2 shows that, although $26.3 \%$ of all observed deaths were thus excluded from the analysis because they occurred before 1951 or within 20 years of first employment, over $90 \%$ of deaths from pneumoconiosis and from lung cancer were included, and percentages were also high for malignant neoplasms of other sites (except the larynx) and stroke. Only small proportions, however, were included of deaths from respiratory tuberculosis $(23.0 \%)$ and from accidents $(39.7 \%)$, with other specific groups of causes intermediate.

When account is taken only of length of service (table 6), trends of risk, as measured by the ratios of observed to expected deaths - that is, SMRs in which the standardisation was by both age and era- 
Table 6 Deaths, by cause, in relation to duration of service

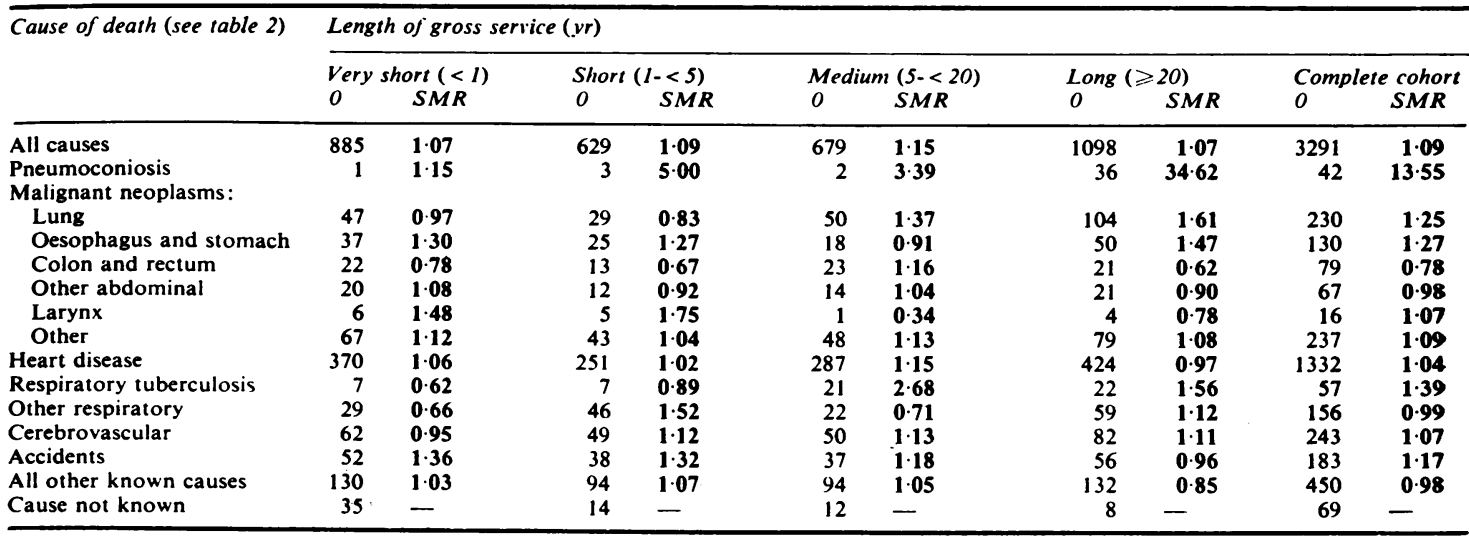

Columns headed 0 give the numbers of deaths of men, 20 years or more after first employment, occurring during 1951-75; figures under headings SMR are ratios of deaths observed to those expected on basis of male mortality in Quebec.

were generally without clear trends, probably reflecting differences in selection and other factors already discussed. Exceptions were deaths attributed to pneumoconiosis and to accidents: of the 42 deaths from pneumoconiosis, 36 were in men with at least 20 years' service; the trend with accidents was in the reverse direction, but it must be emphasised that, as the study interval started only 20 years after first employment, the trend is not a reflection of early work accidents in the asbestos industry shortening service prematurely.

Among those in the very short and short service groups - that is, those with gross service of less than five years (tables 7(a) and (b)) careful study of differences between groups according to severity of exposure showed no consistent pattern. Table 7(c) deals with men with gross service between five and 20 years; their service had also been completed before the start of the study interval. There were fairly consistent trends for higher SMRs the greater the dust exposure for total mortality, for pneumoconiosis (although based on only two deaths), heart disease, and stroke. In addition SMRs were highest in the group with the most severe exposure, for lung cancer and "other" respiratory diseases. All these findings are understandable as pulmonary fibrosis could well contribute directly to cardiopulmonary disease and, in addition, might adversely affect the probability of survival in any lifethreatening condition. Table 7(d) concerns 3105 men

Table 7 Deaths, by cause, in relation to dust concentration (a) Gross service: less than one year

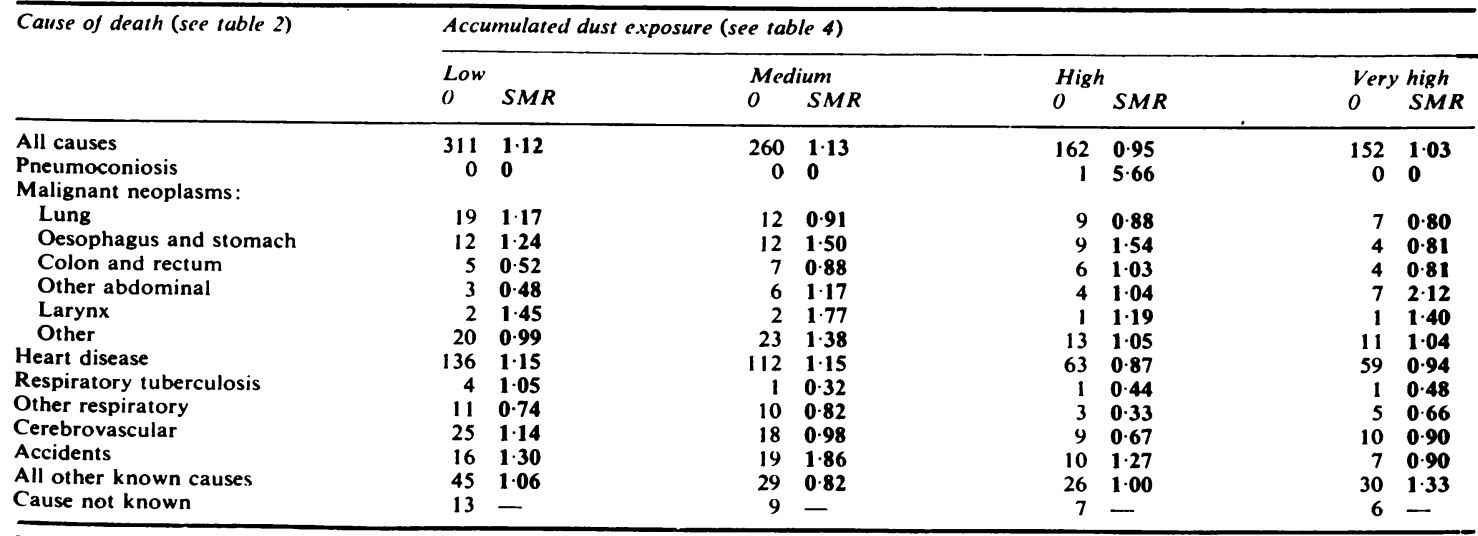

See footnote to table 6 . 
$7(b)$ Gross service: one year, less than five years

\begin{tabular}{|c|c|c|c|c|c|c|c|c|}
\hline \multirow[t]{3}{*}{ Cause of death (see table 2) } & \multicolumn{8}{|c|}{ Accumulated dust exposure (see table 4) } \\
\hline & \multirow{2}{*}{$\begin{array}{l}\text { Low } \\
0\end{array}$} & \multirow{2}{*}{$S M R$} & \multicolumn{2}{|c|}{ Medium } & \multicolumn{2}{|c|}{ High } & \multicolumn{2}{|c|}{ Very high } \\
\hline & & & & $S M R$ & 0 & $S M R$ & 0 & $S M R$ \\
\hline All causes & 141 & $1 \cdot 12$ & 246 & 1.09 & 130 & $1 \cdot 12$ & 112 & 1.04 \\
\hline $\begin{array}{l}\text { Pneumoconiosis } \\
\text { Malignant neoplasms: }\end{array}$ & $\mathbf{0}$ & $\mathbf{0}$ & 3 & 12.80 & $\mathbf{0}$ & $\mathbf{0}$ & $\mathbf{0}$ & $\mathbf{0}$ \\
\hline Lung & 5 & 0.66 & 13 & 0.95 & 6 & 0.82 & 5 & 0.78 \\
\hline Oesophagus and stomach & 8 & 1.83 & 7 & 0.90 & 4 & 1.03 & 6 & 1.64 \\
\hline Colon and rectum & 2 & 0.46 & 4 & $\mathbf{0 . 5 2}$ & 4 & 1.04 & 3 & 0.82 \\
\hline Other abdominal & 2 & 0.70 & 7 & 1.37 & 2 & 0.75 & 1 & 0.41 \\
\hline Larynx & 2 & $3 \cdot 17$ & 1 & 0.89 & 1 & 1.71 & 1 & 1.90 \\
\hline Other & 14 & 1.53 & 16 & 0.98 & 9 & 1.08 & 4 & 0.52 \\
\hline Heart disease & 51 & 0.95 & 99 & 1.03 & 59 & $1 \cdot 19$ & 42 & 0.92 \\
\hline Respiratory tuberculosis & $\mathbf{0}$ & $\mathbf{0}$ & 5 & 1.64 & 1 & 0.61 & 1 & 0.65 \\
\hline Other respiratory & 10 & 1.49 & 16 & $1 \cdot 34$ & 10 & 1.66 & 10 & $1 \cdot 78$ \\
\hline Cerebrovascular & 18 & 1.83 & 17 & 0.98 & 10 & $1 \cdot 19$ & 4 & 0.49 \\
\hline Accidents & 11 & 1.89 & 12 & $1 \cdot 10$ & 3 & 0.47 & 12 & $2 \cdot 14$ \\
\hline All other known causes & 16 & 0.83 & 40 & $1 \cdot 16$ & 16 & 0.91 & 22 & $\mathbf{1 . 3 3}$ \\
\hline Cause not known & 2 & - & 6 & - & 5 & - & 1 & - \\
\hline
\end{tabular}

See footnote to table 6.

7(c) Gross service: five years, less than 20 years

\begin{tabular}{|c|c|c|c|c|c|c|c|c|}
\hline \multirow[t]{3}{*}{ Cause of death (see table 2) } & \multicolumn{8}{|c|}{ Accumulated dust exposure (see table 4) } \\
\hline & \multirow{2}{*}{$\begin{array}{l}\text { Low } \\
0\end{array}$} & \multirow[b]{2}{*}{$S M R$} & \multicolumn{2}{|c|}{ Medium } & \multicolumn{2}{|c|}{ High } & \multicolumn{2}{|c|}{ Very high } \\
\hline & & & 0 & $S M R$ & 0 & $S M R$ & & $S M R$ \\
\hline All causes & 161 & $1 \cdot 10$ & 194 & 1.07 & 170 & 1.22 & 154 & 1.26 \\
\hline Pneumoconiosis & 0 & $\mathbf{0}$ & $\mathbf{0}$ & $\mathbf{0}$ & 1 & $7 \cdot 36$ & 1 & $8 \cdot 42$ \\
\hline \multicolumn{9}{|l|}{ Malignant neoplasms: } \\
\hline Lung & 13 & 1.41 & 14 & $1 \cdot 22$ & 7 & 0.83 & 16 & $2 \cdot 17$ \\
\hline Oesophagus and stomach & 6 & $\mathbf{1 . 2 1}$ & 6 & 0.99 & 5 & 1.07 & 1 & $0 \cdot 25$ \\
\hline Colon and rectum & 4 & 0.81 & 7 & $1 \cdot 14$ & 9 & 1.92 & 3 & 0.74 \\
\hline Other abdominal & 6 & $1 \cdot 78$ & 3 & 0.72 & 3 & 0.95 & 2 & 0.73 \\
\hline Larynx & $\mathbf{0}$ & $\mathbf{0}$ & $\mathbf{0}$ & $\mathbf{0}$ & 1 & 1.44 & $\mathbf{0}$ & $\mathbf{0}$ \\
\hline Other & 9 & 0.85 & 19 & 1.44 & 11 & $1 \cdot 10$ & 9 & 1.03 \\
\hline Heart disease & 66 & 1.06 & 81 & 1.05 & 72 & 1.22 & 68 & 1.31 \\
\hline Respiratory tuberculosis & 3 & 1.55 & 9 & 3.94 & 5 & 2.64 & 4 & $2 \cdot 28$ \\
\hline Other respiratory & 5 & 0.64 & 5 & 0.51 & 5 & 0.69 & 7 & $1 \cdot 12$ \\
\hline Cerebrovascular & 8 & 0.73 & 13 & 0.94 & 14 & 1.34 & 15 & 1.67 \\
\hline Accidents & 8 & 1.07 & 10 & 1.08 & 10 & $\mathbf{1 . 3 3}$ & 9 & $\mathbf{1 . 2 8}$ \\
\hline All other known causes & 29 & $\mathbf{1} \cdot \mathbf{3 0}$ & 21 & 0.77 & 25 & $1 \cdot 17$ & 19 & 1.01 \\
\hline Cause not known & 4 & - & 6 & - & 2 & - & 0 & - \\
\hline
\end{tabular}

Sez footnote to table 6 .

7 (d) Gross service: 20 or more years

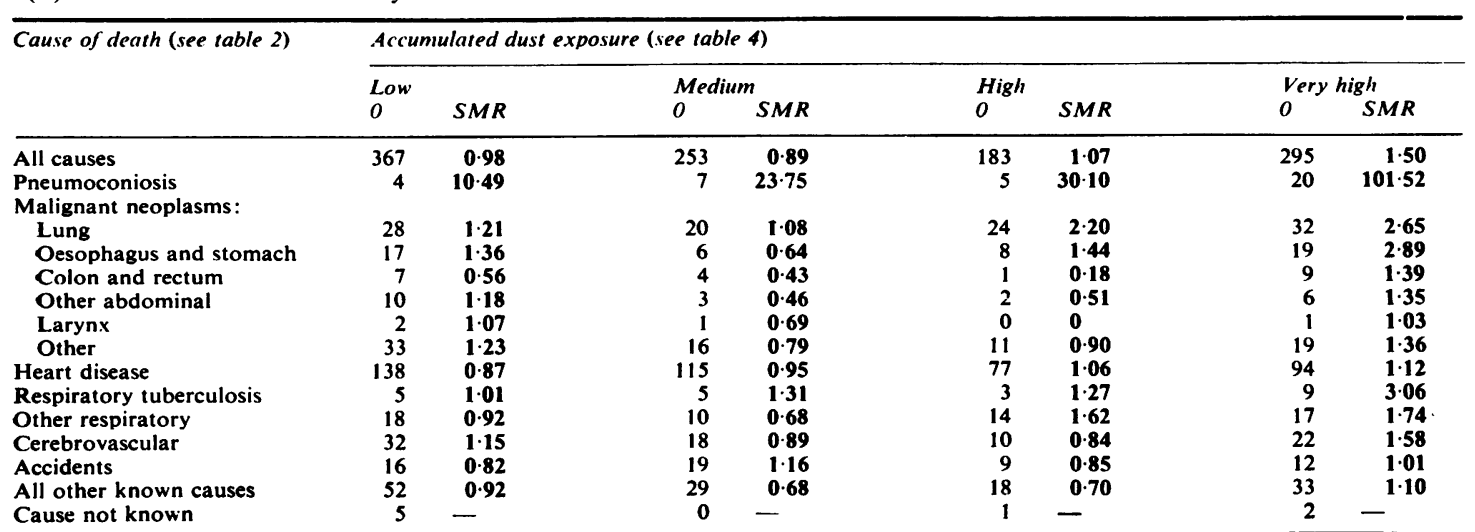

See footnote to table 6 . 
Table 8 Deaths, by cause, in relation to dust exposure accumulated to age 45

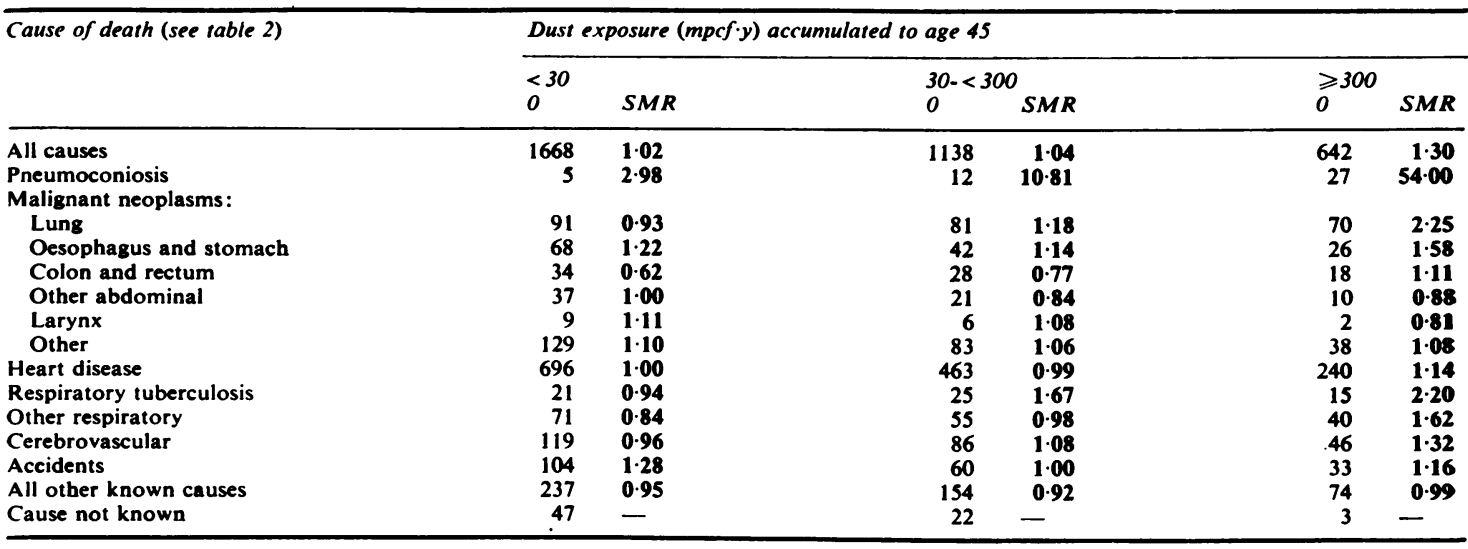

See footnote to table 6 .

with at least 20 years' service, and an average of almost 32 years of employment (table 4). Here, the most severely exposed had the highest SMR not only for total mortality but for all listed causes other than laryngeal cancer and accidents. Further, the tendency for increased risk with each augmentation in exposure was completely consistent for pneumoconiosis and for heart disease, and positive, although rather less consistent, for total mortality, lung cancer, respiratory tuberculosis, and other respiratory diseases.

The other form of a priori analysis, with exposure calculated to age 45 at which age the study interval started, is summarised in table 8 . The total number of deaths observed in this analysis was $3448(77.3 \%$ of all deaths), with SMR $=1.07$, very close to that for all causes in the complete cohort as given in table 6. Indeed, for each cause of death, SMRs from both methods of analysis were always close.

Clear trends were found for SMRs to be higher the heavier the exposure, for total mortality, pneumoconiosis, lung cancer, cancer of colon and rectum, respiratory tuberculosis, other respiratory diseases, and stroke. The trends were most clear-cut in pneumoconiosis and lung cancer, appearing in both Asbestos and Thetford Mines. The lung cancer trend was essentially linear as shown in the figure, where exposures of $30 \mathrm{mpcf} \cdot \mathrm{y}$ or more have been broken down further, into four classes. The trend for respiratory tuberculosis was also consistent in the two areas, but not those for the other causes listed here. The risk of death from cancer of the oesophagus or stomach was highest in the most severely exposed, but only at Thetford Mines; so was the risk of death due to heart disease, but only at Asbestos. Other abdominal cancers and laryngeal cancers were
Table 9 Deaths from lung cancer in relation to dust exposure and smoking habit

\begin{tabular}{|c|c|c|c|c|}
\hline \multirow[t]{2}{*}{ Smoking habit* } & \multicolumn{4}{|c|}{ Dust exposure $(m p c f \cdot y)$ accumulated to age 45} \\
\hline & $\begin{array}{l}<30 \\
0 S M R\end{array}$ & $\begin{array}{l}30-<300 \\
0 S M R\end{array}$ & $\begin{array}{l}\geqslant 300 \\
0 S M R\end{array}$ & $\begin{array}{l}\text { All } \\
0 \text { SMR }\end{array}$ \\
\hline $\begin{array}{l}\text { Non-smokers } \\
\text { Moderate smokers } \\
\text { Heavy smokers } \\
\text { All smoking habits }\end{array}$ & $\begin{array}{rr}5 & 0 \cdot 18 \\
73 & 1 \cdot 14 \\
13 & 2 \cdot 12 \\
91 & 0 \cdot 93\end{array}$ & $\begin{array}{rr}6 & 0.36 \\
64 & 1 \cdot 35 \\
11 & 2 \cdot 39 \\
81 & 1 \cdot 18\end{array}$ & $\begin{array}{rr}8 & 1 \cdot 24 \\
52 & 2 \cdot 31 \\
10 & 4 \cdot 50 \\
70 & 2 \cdot 25\end{array}$ & $\begin{array}{rr}19 & 0.38 \\
189 & 1.41 \\
34 & 2 \cdot 63 \\
242 & 1.23\end{array}$ \\
\hline
\end{tabular}

See footnote to table 6 .

* See text for definitions.

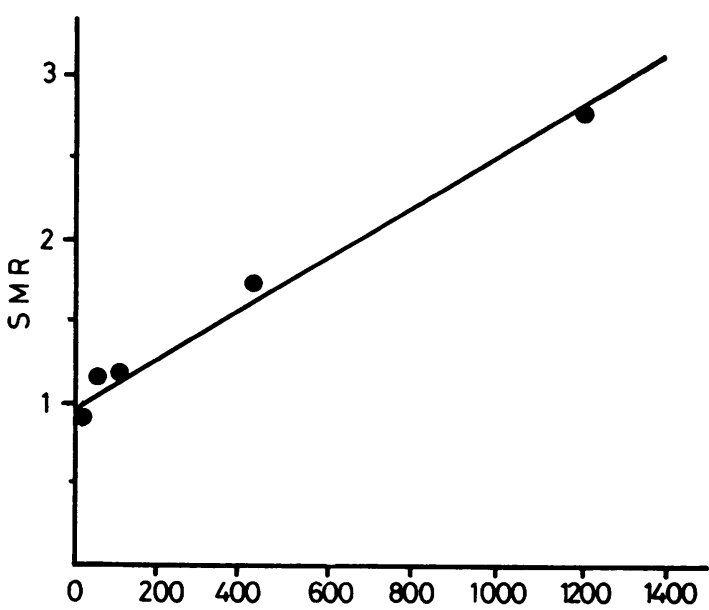

Dust exposure (mpct.y) accumulated to age 45

Lung cancer SMRs in relation to dust exposure accumulated to age 45. The line has been fitted by a modified least-squares technique. 
inversely related to exposure, and no other patterns could be elucidated.

The last line of table 9 is repeated from the previous table, but the right-hand margin shows a clear and substantial effect of cigarette smoking. For each category of smoker, the risk of lung cancer was lowest among those with low exposure to age 45 and highest among those with exposure of at least 300 mpcf.y by that age. The interaction between the factors of smoking and dust exposure is examined later (table 11).

Corresponding detail for laryngeal cancer is confusing because of the very small number of deaths from this cause. As already seen (table 8), the dust effect was, if anything, inverse; however, the smoking effect was quite strong-non-smokers: two deaths, SMR $=0.46$; moderate smokers: 10 deaths, SMR $=0.93 ;$ heavy smokers: five deaths, $\mathrm{SMR}=4 \cdot 85$.

Table 10 summarises the findings from the Miettinen approach-that is, more than one control

Table 10 Dust exposure in deaths from pneumoconiosis and from malignant disease and in controls

\begin{tabular}{|c|c|c|c|c|c|}
\hline & \multicolumn{5}{|c|}{$\begin{array}{l}\text { Dust exposure (mpct y) accumulated up to nine } \\
\text { lears before death of case }\end{array}$} \\
\hline & $<30$ & $30-<300$ & $300-<1000$ & $\therefore 1000$ & All \\
\hline \multicolumn{6}{|l|}{ Pneumoconiosis } \\
\hline Deaths & 7 & 9 & 13 & 17 & 46 \\
\hline Controls $(3)^{*}$ & 63 & 49 & 21 & 5 & 138 \\
\hline Relative risk ${ }^{+}$ & 1 & $1 \cdot 65$ & $5 \cdot 57$ & $30 \cdot 60$ & - \\
\hline \multicolumn{6}{|l|}{ Lung cancer } \\
\hline Deaths + & 89 & 73 & 56 & 27 & 245 \\
\hline Controls (3) & 333 & 243 & 127 & 32 & 735 \\
\hline Relative risk & 1 & $1 \cdot 12$ & $1 \cdot 65$ & $3 \cdot 16$ & - \\
\hline \multicolumn{6}{|c|}{ Cancer of oesophagus and stomach } \\
\hline Deaths & 74 & 41 & 22 & 17 & 154 \\
\hline Controls (2) & 143 & 105 & 53 & 7 & 308 \\
\hline Relative risk & 1 & 0.75 & 0.80 & $4 \cdot 69$ & - \\
\hline \multicolumn{6}{|c|}{ Cancer of colon and rectum } \\
\hline Deaths & 39 & 29 & 13 & 7 & 88 \\
\hline Controls (2) & 88 & 70 & 15 & 3 & 176 \\
\hline Relative risk & 1 & 0.93 & 1.96 & $5 \cdot 26$ & - \\
\hline \multicolumn{6}{|c|}{ Other abdominal cancers } \\
\hline Deaths & 43 & 25 & 7 & 5 & 80 \\
\hline Controls (2) & 83 & 46 & 26 & 5 & 160 \\
\hline Relative risk & 1 & $1 \cdot 05$ & 0.52 & 1.93 & $\longrightarrow$ \\
\hline \multicolumn{6}{|l|}{ Cancer of larynx } \\
\hline Deaths & 13 & 6 & 2 & 0 & 21 \\
\hline Controls (3) & 36 & 21 & 5 & 1 & 63 \\
\hline Relative risk & 1 & 0.79 & 1.11 & 0.00 & - \\
\hline
\end{tabular}

* Figures in brackets are numbers of controls for each death. Method of selecting controls is described in text; those reported here were not matched for smoking habit.

+ Risk calculated by method of Doll ${ }^{25}$ in relation to those with exposure less than $30 \mathrm{mpcf} \cdot \mathrm{y}$.

\$Excluding five deaths coded to $162-164$, but found to be due to malignant mesothelioma. for each case, excluding those for smoking habit; the numbers of deaths are as in table 2 (but see footnote $\ddagger$ in table 10 ) because there were no restrictions on the start of the study interval. Four groups of dust exposure are distinguished, and the data are presented without regard to the matching. Matching was taken into account in the full analysis, however, which generally confirmed the tendencies shown in the two a priori approaches (Thomas, DC, unpublished), and relative risks were fairly similar at Asbestos and Thetford Mines.

Table 11 Dust exposure in deaths from lung cancer and in controls matched for smoking habit

\begin{tabular}{|c|c|c|c|c|c|}
\hline & \multicolumn{5}{|c|}{$\begin{array}{l}\text { Dust exposure }(m p c f \cdot y) \text { accumulated up to nine } \\
\text { lears before death of case }\end{array}$} \\
\hline & $<30$ & $30-<300$ & $300-<1000$ & $\geqslant 1000$ & All \\
\hline \multicolumn{6}{|l|}{ Non smokers } \\
\hline Deaths & 5 & 5 & 5 & 5 & 20 \\
\hline Controls* & 10 & 6 & 3 & 1 & 20 \\
\hline Relative risk + & 1 & 1.67 & $3 \cdot 33$ & $10 \cdot 00$ & - \\
\hline \multicolumn{6}{|c|}{ Smcking habit undifferentiated } \\
\hline Deaths & 43 & 23 & 22 & 12 & 100 \\
\hline Controls & 49 & 33 & 17 & 1 & 100 \\
\hline Relative risk & 1 & 0.79 & 1.47 & 13.67 & - \\
\hline \multicolumn{6}{|c|}{ Definite cigarette smokers } \\
\hline Deaths & 41 & 45 & 29 & 10 & 125 \\
\hline Controls & 49 & 48 & 22 & 6 & 125 \\
\hline Relative risk & 1 & $1 \cdot 12$ & $1 \cdot 58$ & 1.99 & - \\
\hline \multicolumn{6}{|c|}{ All smoking habits } \\
\hline Deaths + & 89 & 73 & 56 & 27 & 245 \\
\hline Controls & 108 & 87 & 42 & 8 & 245 \\
\hline Relative risk & 1 & 1.02 & $1 \cdot 62$ & $4 \cdot 10$ & - \\
\hline
\end{tabular}

* One control for each death.

$+R$ isk calculated by method of Doll ${ }^{25}$ in relation tc those with exposure less than 30 mpcf $y$.

\#Excluding five deaths coded to $162-164$, but found to be due to malignant mesothelioma.

The interaction between dust exposure and smoking in lung cancer mortality is explored in table 11, where the distribution of dust exposure of the single control matched so far as possible for smoking is compared with that of the cases in each smoking category separately. The final section of this table differs from the corresponding part of the previous table because of the different selection of controls, but the relative risks are similar. Further, the relative risks within smoking categories are in reasonable accord with those obtainable from table 9, despite major differences in the methods of determining them.

Clearly lung cancer can occur in non-smokers, and indeed it might seem from our data that the relative risk due to asbestos dust exposure was, in fact, higher for non-smokers than for smokers. Linear 
dose-response relations have been fitted (Berry, G, unpublished), so far without regard for smoking: using the data on which table 10 is based, but taking into account the matching of controls for each case in terms of date of birth and place of employment, the fitted line was

Relative risk $=1+0.0014$ (mpcf.y)

the standard error of the estimate of the slope being 0.0005 . The linear fit accounted for $\chi^{2}$, with one degree of freedom, of $21 \cdot 37$, leaving only a very low value for deviations from linearity.

There were in all 11 deaths (including one of a woman) from malignant mesothelial tumours observed to the end of 1975. All were of the pleura and appeared to follow a clear exposure trend. The problems of interpretation are complex, however, and the subject will be examined in detail elsewhere. ${ }^{11}$

\section{W OMEN}

Of the $\mathbf{4 4 0}$ women in the cohort, only $\mathbf{3 1}$ were lost to view $(7.0 \%)$, a better rate of tracing than for men. Of those traced, 325 were alive until $1976(79.5 \%)$ and 84 had died $(20.5 \%)$, the lower percentage mortality than in the men being largely explained by the younger age of the women. The women had been employed mainly at Asbestos (408 (92.7\%)), and only $84(19.1 \%)$ had been exposed to more than 30 mpcf.y by age 45 . In addition to the case of pleural mesothelioma mentioned above, there was one death from lung cancer, compared with 1.19 expected. Careful study of the remaining detail showed no other exposure-related effect.

\section{Discussion}

This survey, begun in 1966 and continued without interruption for 12 years, has sought to determine the quantitative relations between occupational exposure in the chrysotile production industry of Quebec and mortality. Since analyses conducted at four stages during the 10-year period, by increasingly varied and sophisticated statistical methods, have been closely consistent, ${ }^{3}$ we conclude that our objective has been achieved. Essentially linear relations have been shown between indices of exposure, based on dust concentration (mpcf) multiplied by length of service, and lung cancer, pneumoconiosis, and total number of deaths. Using this measure of environmental quality, we are now able to assess, with reasonable confidence, the mortality risk associated with work at different levels of dust concentration and for social decisions to be made as to what level, if any, is "acceptable."12 As almost half of the cohort is now dead, no further study would appear necessary were it not for the current trend toward setting hygiene standards in terms of fibre rather than dust counts-despite the almost complete lack of epidemiological data based on fibre measurements. There would be no serious problem were the conversion a simple one. The evidence of Gibbs and Lachance ${ }^{13}$ shows that this is not the case and so we have now embarked on a laborious attempt to estimate past exposures in fibres $/ \mathrm{ml}$ and will use these in further analyses of our mortality and morbidity findings. In the meantime we may note the results of an analysis of Gibbs's data by Dagbert, 14 which showed that, at the relevant dust levels, the conversion factors range from about 3 to 7 fibres $/ \mathrm{ml}$ for each mpcf. Further data now available to us, however, point to a lower range, perhaps 1 to 5 .

When considering what degree of environmental exposure can be regarded as "safe," a linear response to exposure is a great convenience. ${ }^{315}$ It allows extrapolation to exposure levels far below those at which reliable direct measurement of risk is possible. Our findings by two methods of analysis conform well with the hypotheses of linearity, but they do not constitute proof. It is not unreasonable, however, to suppose that the probability of initiation of the malignant process by mutation may be dose-related and that defence mechanisms will not change this.

Similar uncertainty remains over the form of interaction between asbestos exposure and cigarette smoking. Our data seem as compatible with the "additive model" of relative risk (model 1) discussed by Saracci,16 as with the "multiplicative model" - that is, with the simplest form of his model 2; they are quite incompatible with model 3 , in which "asbestos can only increase lung cancer in the presence of smoking." Either model allows one to speculate that the dust concentrations in the Quebec mills in the early 1950 s, before effective dust suppression was introduced, carried a lung cancer risk equivalent to heavy smoking whereas, at more recent concentrations of around $1 \mathrm{mpcf}$, the order of risk may now approximate to less than one cigarette a day. Despite the much greater sophistication of the "matched" case-control analyses of the data (Thomas, DC, unpublished), they gave essentially the same results as our "unmatched" analysis, and so far have not been able to increase confidence in the exact form of the interaction.

Several factors bearing on the validity of this survey warrant examination. A study of this kind is as good as the environmental and mortality records on which it is based. On the former we can add little: the very large number of environmental measurements made in this industry since about 1950 have been used to the full, but for the more important earlier years we have only our estimates to go on. 
While this is frankly acknowledged, two points can be made: (1) the estimates were based on many years of extensive study of Quebec mines and mills with very varied hygiene standards; and (2) random errors in exposure estimates would have been expected to obscure rather than enhance correlation between exposure and response.

At least equal effort was put into the follow-up and ascertainment of registered causes of death. In terms of completeness we believe this satisfactory; almost all of the $10 \%$ of subjects lost to view were men with short service many years ago; over $98 \%$ were traced after 1935 and a cause was obtained for $97 \%$ of deaths.

Questions remain, however, on the validity of recorded cause of death and on possibilities of related bias. These questions apply only to cause of death and not to the fact of death-the more important issue. It must be faced that, in this, as in other occupational cohort studies, there is considerable scope for diagnostic bias. In writing a death certificate most physicians prefer probable to improbable causes; men who die of respiratory disease after long heavy exposure to dust could well have had pneumoconiosis, whereas this must be considered unlikely in men without such history. Selective necropsies will, if anything, increase this type of bias. Even a $100 \%$ necropsy rate in the study population would overcome the problem only if the same population is used as the basis for calculating expectations. The net result, discussed in our first report on this cohort, ${ }^{4}$ is that there may be a bias towards the over diagnosis of dust-related disease in men with heavy exposure. The effect will be intensified by a greater frequency of necropsies in deaths where a prima facie case for compensation exists. There was evidence of this in the high necropsy rate $(52 \%)$ in deaths ascribed to pneumoconiosis. The effect of this trend might well overflow into those causes of death-especially cancer of the lung and other organs-which are under-diagnosed without necropsy. None of this, however, affects the validity of the exposure-response relation for deaths (all causes), although conceivably it contributes to the linearity and excess for pneumoconiosis and lung cancer.

A related problem in cohort studies is the so-called "healthy worker effect" (see, for example, Fox and Collier ${ }^{17}$ ) resulting from non-random selective entry and exit from various industries and for jobs within the industries. It is an unfortunate term because these selective forces, dependent on circumstances, may result in healthy or unhealthy worker effects. These effects matter because no observational study in epidemiology can correct for them; this is especially so in a priori analyses of the man-years type using an external reference population. Tables 6, 7(a), and 7(b) show some of the problems of interpretation: men with gross service less than five years $(a)$ had about the same SMRs for all causes $(1.07,1.09)$ as those with long service (1.07); and (b) had SMRs that were higher at the lower exposure levels. Part of the explanation may be that the less fit went to the less heavy or less dusty jobs and often did not stay long in the industry. Another part may be that those with the shortest employment were the most difficult to trace, and among them death was probably more completely ascertained than survival, but this effect must be small because of the high trace rate actually achieved - that is, more than $99 \%$ after 1950 .

This survey, and related research, in the chrysotile production industry were undertaken because of the critically important need, expressed in $1964,{ }^{1}$ for studies to compare the pathogenicity of the main asbestos fibre-types. A survey ${ }^{18}$ of the much smaller Italian chrysotile mining industry has yielded findings very similar to our own; unfortunately, no comparable observations have been made on crocidolite or amosite production. Nor have there been any reports on mortality after exposure to single asbestos fibre-types in manufacturing or application, in which exposure was measured in more than duration. Two small factories working with chrysotile only were studied by Elwood ando Cochrane ${ }^{19}$ and Weiss, ${ }^{20}$ a large plant with amosite only by Selikoff and Hammond, ${ }^{21}$ and a small group with crocidolite only by McDonald and McDonald.22 Because dust or fibre concentrations were not measured in these studies, comparisons of frequency of lung fibrosis and cancer cannot be made with confidence, although the evidence all points in the direction of more serious effects from the amphiboles than from chrysotile. The incidence of malignant mesothelial tumours, especially of the peritoneum, is so very much higher after exposure to amphiboles (and amphibole-rich mixtures) than after exposure to chrysotile alone, that differences in dust concentration are unlikely to explain it. ${ }^{22-24}$

As in earlier reports on the Quebec cohort, the patterns of gastrointestinal cancer are difficult to interpret. There was unquestionably a substantial excess in mortality from cancer of the upper gastrointestinal tract in men most heavily exposed. This excess was confined to Thetford Mines where most of the long and heavy exposures occurred. The exposure-response curves were far from regular, however, and it appears that some other important factors were also operating-perhaps selective, perhaps environmental. The SMR for cancer of the lower gastrointestinal tract for the complete cohort was 0.78 (table 6); nevertheless, there was some 
evidence of an exposure-response trend.

Our findings on laryngeal cancer are clear cut, although others' have not been so. There has been no excess in this industry, and there is no quantitative association with exposure; on the other hand, we find a direct relation with cigarette smoking.

Because an important current concern is the risk from concentrations of asbestos dust nearer to today's standards, we have re-examined our data for the 1904 men in the cohort employed for at least 20 years in the low and medium dust exposure groups. The concentrations to which these men were exposed (see table 4 and footnote*) averaged 6.6 mpcf, or perhaps $20 \mathrm{fibres} / \mathrm{ml}$, and thus were much above anything permissible now. Nevertheless, as can be deduced from table 7 (d), the total mortality in the study interval was $\mathbf{6 2 0}$ deaths, and the SMR was 0.94 . This may well be a true healthy worker effect. but not all cause-specific SMRs were below unity. Indeed, there were excesses for pneumoconiosis (10.3 excess deaths, leading to $\chi^{2}$ on the usual basis, and with one degree of freedom, of 159.27), for lung cancer $\left(6.4, \chi^{2}=0.99\right)$; cancer of oesophagus and stomach $\left(1 \cdot 1, \chi^{2}=0.06\right)$; "other" cancers $\left(1.7, \chi^{2}=0.06\right)$; respiratory tuberculosis $(1.3$, $\left.\chi^{2}=0.17\right)$; and stroke $\left(1.8, \chi^{2}=0.07\right)$. Apart from pneumoconiosis, these values of $\chi^{2}$ are so low, even for lung cancer (where the associated p-value is $32.0 \%$ ), that the observed excesses do not reach conventional levels of statistical significance. Moreover, the lung cancer SMR for the low dust exposure group $(1.21)$ was higher than that $(1.08)$ for the medium exposure group; only the greatly enhanced SMRs for those with high and very high exposure allow the conclusion that there was a response to exposure. Nevertheless, the lung cancer SMR for all 1904 men was $1 \cdot 15$, in close conformity with that which might be predicted from the figure (around 1.20 ), or the relative risk of 1.16 from the fitted line (Berry, G, unpublished). By their nature, epidemiological surveys, however large, cannot achieve greater precision than the one described here. Hence the clear importance of deciding whether a linear exposure-response model should be adopted, if only for practical reasons.

This survey was made possible by the contribution of many people and agencies, in private or official capacity. We would mention, in particular, Mmes $\mathbf{M}$ Beauchemin and F Proulx for their work in maintaining contact with ex-employees, Dr J M Fredette for help in finding death certificates, and Mmes $\mathbf{M}$ Gauthier and C Tessier for coding them. We had the active co-operation throughout of the mining companies and the several trades unions with members in the industry. Grants toward the cost of the research were made to McGill University and to the London School of Hygiene and Tropical Medicine by the Institute of Occupational and Environmental Health of the Quebec Asbestos Mining Association.

\section{References}

${ }^{1}$ Report and recommendations of the Working Group on Asbestos and Cancer. International Union against Cancer (UICC). Ann NY Acad Sci 1965;132:706-21.

2 McDonald JC, Becklake MR, Gibbs GW, McDonald AD, Rossiter CE. The health of chrysotile asbestos mine and mill workers of Quebec. Arch Environ Health 1974; 28:61-8.

${ }^{3}$ McDonald JC, Liddell FDK. Mortality in Canadian miners and millers exposed to chrysotile. Ann NY Acad Sci (in press).

+ McDonald JC, McDonald AD, Gibbs GW, Siemiatycki J, Rossiter CE. Mortality in the chrysotile asbestos mines and mills of Quebec. Arch Environ Health 1971;22: 677-86.

5 McDonald JC, Rossiter CE, Eyssen G, McDonald AD. Mortality in the chrysotile producing industry of Quebec: a progress report. In: Proceedings of the IVth International Pneumoconiosis Conference, Bucharcst, 1971. Bucharest: Apimondia, 1973:232-7.

- Liddell FDK, McDonald JC, Thomas DC. Methods of cohort analysis: appraisal by application to asbestos mining. J R Stat Soc. Series A 1977;140:469-91.

- Gibbs GW, Lachance M. Dust exposure in the chrysotile asbestos mines and mills of Quebec. Arch Environ Health 1972;24:189-97.

${ }^{8}$ Case RAM, Lea AJ. Mustard gas poisoning, chronic bronchitis, and lung cancer. BrJ Prev Soc Med 1955; 9:62-72.

- Liddell FDK. Occupational mortality in relation to exposure. Arch Environ Health 1975;30:266-7.

10 Miettinen OS. Individual matching with multiple controls in the case of all-or-none response. Biometrics 1969;25: 339-55.

11 McDonald AD. Malignant mesothelioma in Quebec. IARC Symposium on the Biological Effects of Mineral Fibres, Lyon, 25-27 September 1979.

12 McDonald JC. Problems in the determination of safety standards for asbestos-exposed workers. Hefte zur Unfallheilkunde, Heft 126: 2. Deutsch-OsterreichischSchweizerische Unfalltagung in Berlin 1975. Berlin and Heidelberg: Springer-Verlag, 1976.

${ }^{13}$ Gibbs GW, Lachance $M$. Dust-fiber relationships in the Quebec chrysotile industry. Arch Environ Health 1974; 28:69-71.

1 Dagbert M. Etude de Corrélation des Mesures d'Empoussièrage dans l'Industrie de l'Amiante. Document 5. Quebec: Comité d'étude sur la salubrité dans l'industrie de l'amiante (Président: René Beaudry, jcp).

15 Peto J. The hygiene standard for chrysotile asbestos. Lancet 1978;1:484-9.

10 Saracci R. Asbestos and lung cancer: an analysis of the epidemiological evidence on the asbestos-smoking interaction. Int J Cancer 1977;20:323-31.

${ }^{17}$ Fox AJ, Collier PF. Low mortality rates in industrial cohort studies due to selection for work and survival in the industry. Br J Prev Soc Med 1976;30:225-30.

18 Rubino GF, Scansetti G, Piolatto G. Asbestos Hazards in Italy. Presented at a meeting of the Royal Society of Medicine, London, 28 April 1977. 
19 Elwood PC, Cochrane AL. A follow-up study of workers from an asbestos factory. Br J Ind Med 1964;21:304-7.

${ }^{20}$ Weiss W. Mortality of a cohort exposed to chrysotile asbestos. JOM 1977;19:737-40.

${ }^{21}$ Selikoff IJ, Hammond EC. Multiple risk factors in environmental cancer. In: Proceedings of Conference on Persons at High Risk of Cancer: an Approach to Cancer Etiology and Control, December 10-12 1974. Key. Biscayne, Florida, 1975.

22 McDonald AD, McDonald JC. Mesothelioma after crocidolite exposure during gas mask manufacture.
Environ Res 1978;17:340-6.

${ }^{23}$ McDonald JC, McDonald AD. Epidemiology of mesothelioma from estimated incidence. Prev Med 1977;6:426-46.

24 McDonald JC. Exposure relationships and malignant mesothelioma. In: Glen $\mathrm{HW}$, ed. Proceedings of Asbestos Symposium, Johannesburg 3-7 October 1977. Randburg: National Institute for Metallurgy, 1978.

${ }^{25}$ Doll R. Retrospective and prospective studies. In: Witts LJ, ed. Medical surveys and clinical trials. London: Oxford University Press, 1964:84-5.

\section{Vancouver style}

All manuscripts submitted to Occup Environ Med should conform to the uniform requirements for manuscripts submitted to biomedical journals (known as the Vancouver style.)

Occup Environ Med, together with many other international biomedical journals, has agreed to accept articles prepared in accordance with the Vancouver style. The style (described in full in the $B M F, 24$ February 1979 , p 532) is intended to standardise requirements for authors.

References should be numbered consecutively in the order in which they are first mentioned in the text by Arabic numerals above the line on each occasion the reference is cited (Manson ${ }^{1}$ confirmed other reports ${ }^{2-5} \ldots$. . . In future references to papers submitted to Occup Environ Med should include: the names of all authors if there are seven or less or, if there are more, the first six followed by et al; the title of journal articles or book chapters; the titles of journals abbreviated according to the style of Index Medicus; and the first and final page numbers of the article or chapter. Titles not in Index Medicus should be given in full.

Examples of common forms of references are:

1 International Steering Committee of Medical Editors, Uniform requirements for manuscripts submitted to biomedical journals. Br Med f 1979;1:532-5.

2 Soter NA, Wasserman SI, Austen KF. Cold urticaria: release into the circulation of histamine and eosinophil chemotactic factor of anaphylaxis during cold challenge. $N$ Engl $f$ Med 1976;294:687-90.

3 Weinstein L, Swartz MN. Pathogenic properties of invading micro-organisms. In: Sodeman WA Jr, Sodeman WA, eds. Pathologic physiology, mechanisms of disease. Philadelphia: W B Saunders, 1974:457-72. 